\title{
Research on Seismic Damage Model of CFST Arch- Column Structure Considering of Single Aftershock
}

\author{
Yong $\mathrm{Xu}^{1,2}$, Cuiying $\mathrm{Zhou}^{1, *}$ and Airong $\mathrm{Liu}^{2,3}$ \\ ${ }^{1}$ School of Engineering, Sun Yat-sen University, China \\ ${ }^{2}$ Civil Engineering School, Guangzhou University, China \\ ${ }^{3}$ Guangzhou University-Danjiang University (Taiwan) Join Research Center for Engineering Structure Disaster Prevention and \\ Control, China \\ ${ }^{*}$ Corresponding author
}

\begin{abstract}
To study epicenter intensity model of aftershock, regression analysis on 68 sets data of main shocks and their aftershocks have done, epicenter intensity linear model has researched. According to analysis of earthquake parameters such as peak ground acceleration (PGA), ground motion duration, spectrum intensity factor, they are reasonable to obtain aftershock parameters by appropriately reducing their main shocks'. Equivalent earthquake waves were formed by combining various main shock waves and their corresponding aftershock waves. Using elastic plastic time history analysis of some concrete filled steel tube (CFST) arch column structure, displacement and hysteretic energy indexes in different fortification intensity have obtained under main shock and equivalent earthquake. Using damage index correction coefficient, Park-Ang model was modified to evaluation structure damage which show damage index increased about $7 \% \sim 20 \%$ by thinking of single strongest aftershock, and lower fortification intensity is, bigger damage index increase. Through the calculation of two software, the reliability of the model was verified.
\end{abstract}

Keywords-mainshock; aftershock; energy method; displacement method; seismic damage model

\section{INTRODUCTION}

Using deformation and cumulative hysteretic energy dissipation parameters, Park-Ang model has been proposed and amended to consider main shock damage evaluation in [13].

As a natural phenomenon, aftershocks always company with their main shocks. When some structures have damaged in main shock, then strong aftershock often led to its mechanical properties deterioration. For example, a lot of buildings of Ying-Xiu middle school collapsed in strong aftershock instead of in main shock during Wenchuan earthquakes, so aftershocks should be pay more attention in structural design stage. However, seismic codes rarely presented theory or method of aftershocks. , and two strongest aftershocks model also has been put forward in [4-6]

To simplify design work, single strongest aftershock statistical model and its vibration parameters have been studied. Using two finite element analysis software, seismic damage correction model, which based in Park-Ang model, has been discussed by introducing damage correction coefficient.

\section{QUANTITY OF AFTERSHOCK PARAMETERS}

\section{A. Epicenter Intensity}

From the database of China Earthquake Networks Center (CENC) and Pacific earthquake engineering research center (PEER), 68 sets data of main shocks and their aftershocks which break during 1970 and 2009 have received, and epicenter intensity regression equation can express with least square method as follow in[7]:

$$
I_{a}=0.474 I_{m}+2.506
$$

$I_{a}$ for aftershock epicenter intensity and $I_{m}$ for main shock epicenter intensity. Equation (1) shows that epicenter intensity of main shock and its aftershock were positive correlated. Main shock and its aftershock epicenter intensity can calculated as TABLE I. So, aftershock epicenter intensity can obtain by reducing main shock epicenter intensity, in a word, it is safe to obtain aftershock epicenter intensity by reducing $0.5,1,1.5$ or 2 according to main shock epicenter intensity $6,7,8$ or 9 .

\section{B. Peak Ground Acceleration (PGA)}

Suppose there are the same relationship between PGA and intensity of epicenter in aftershock and its main shock, then epicenter PGA in aftershock can calculated from (1) by confirming epicenter intensity in its main shock. So epicenter PGA in aftershock can predicted as TABLE II according to Code for seismic design of buildings of China. $A_{m}$ for epicenter PGA in main shock and $A_{a}$ for epicenter PGA in aftershock.

\section{Ground Motion Duration}

Horizontal earthquake ground motion attenuation laws of duration is shown as follows in [8]:

$$
\lg T_{\mathrm{s}}=-1.555+0.165 M+0.831 \lg (R+30)+0.148 T_{g}
$$

$T_{\mathrm{s}}$ for ground motion duration, $M$ for magnitude, $R$ for epicenter distance, and $T_{\mathrm{g}}$ for site characteristic period. Suppose ground motion duration of aftershock and its main shock can be expressed as (2), when site is class II, 
classification is first group, $R=20 \mathrm{~km}$ and $T_{\mathrm{g}}=0.35 \mathrm{~s}$, ground motion duration of aftershock and its main shock can obtain from TABLE III.

\section{Spectrum Characteristics}

Using stationary filtered colored noise model, spectral density of acceleration time history is represented as follows in [9]:

$$
\begin{aligned}
& S_{A}(\omega)=\frac{1+4 \xi_{g}^{2} \frac{\omega^{2}}{\omega_{g}^{2}}}{\left(1-\frac{\omega^{2}}{\omega_{g}^{2}}\right)^{2}+4 \xi_{g}^{2} \frac{\omega^{2}}{\omega_{g}^{2}}} \cdot \frac{1}{1+\frac{\omega^{2}}{\omega_{h}^{2}}} S_{0} \\
& \lg S_{0}=2\left[b_{1}+b_{2} M+b_{3} \lg (R+30)+b_{4} T_{g}\right]-2 \lg r-\lg \beta \\
& r=\sqrt{2 \ln \left(v_{A} T_{s}\right)+\frac{0.5772}{\sqrt{2 \ln \left(v_{A} T_{s}\right)}}} \\
& v_{A}=\frac{1}{\pi} \frac{\sigma_{\dot{A}}}{\sigma_{A}}=\frac{1}{\pi} \sqrt{\frac{8 \xi_{g}^{3} \omega_{h}+4 \xi_{g}^{2} \omega_{g}+\omega_{g}}{4 \xi_{g}^{2} \omega_{h}+2 \xi_{g} \omega_{g}+\omega_{h}} \omega_{g} \omega_{h}} \\
& \beta=\frac{4 \xi_{g}^{2} \omega_{h}+2 \xi_{g} \omega_{g}+\omega_{h}}{\omega_{h}^{2}+2 \xi_{g} \omega_{g} \omega_{h}+\omega_{g}^{2}} \frac{\pi \omega_{g} \omega_{h}}{2 \xi_{g}}
\end{aligned}
$$

$\omega_{g}$ for dominant frequency of covering soil, $\xi_{\mathrm{g}}$ for damping ratio of covering soil, $\omega_{h}$ for spectral parameter, $\omega$ for vibrate frequency, $S_{0}$ for spectrum density factor, $v_{A}$ for zero crossing rate, and $b_{1} \sim b_{4}$ for the regression coefficients. Suppose ground motion spectrum of aftershock and its main shock can be expressed as $(3) \sim(7)$, when site is class II, classification is first group, $R=20 \mathrm{~km}$ and $T_{\mathrm{g}}=0.35 \mathrm{~s}$, spectrum intensity factor of aftershock and its main shock can obtain from TABLE IV.

\section{Analysis on Seismic Damage Correction Model}

\section{A. Analysis Model of Structure}

To correct seismic damage model considering interaction of main shock and single aftershock, a concrete filled steel tubular (CFST) arch structure which was composed of two Ibeams steel reinforced concrete (SRC) column and a CFST

\begin{tabular}{|c|c|c|c|c|c|}
\hline \multicolumn{2}{|c|}{$\begin{array}{l}\text { Main Shock Epicenter } \\
\text { Intensity, } I_{m}\end{array}$} & 6 & 7 & 7 & 9 \\
\hline \multirow{2}{*}{$\begin{array}{c}\text { Aftershock } \\
\text { Epicenter } \\
\text { Intensity, } I_{a}\end{array}$} & Calculation & 5.4 & $5.8(6.1)$ & $6.3(6.5)$ & 6.8 \\
\hline & Suggestion & 5.5 & $6.0(6.5)$ & $6.5(7.0)$ & 7.0 \\
\hline
\end{tabular}
arch rib assembled as Figure I was selected. Strength grade of concrete is $\mathrm{C} 35$, thickness of protective layer is $25 \mathrm{~mm}$.

TABLE I. RELATIONSHIP OF EPICENTER INTENSITY BETWEEN MAIN SHOCK AND AFTERSHOCK

The data in round brackets are the corresponding values of $0.15 \mathrm{~g}$ and $0.30 \mathrm{~g}$ basic acceleration.
TABLE II. RELATIONSHIP BETWEEN INTENSITY AND PGA IN EPICENTER

\begin{tabular}{|c|c|c|c|c|}
\hline $\begin{array}{c}\text { Main Shock Epicenter } \\
\text { Intensity, } \boldsymbol{I}_{\boldsymbol{m}}\end{array}$ & $\mathbf{6}$ & $\mathbf{7}$ & $\mathbf{8}$ & $\mathbf{9}$ \\
\hline $\begin{array}{c}\text { Main Shock Epicenter } \\
\text { PGA, } \boldsymbol{A}_{\boldsymbol{m}}\left(\mathbf{c m} / \mathbf{s}^{\mathbf{2}}\right)\end{array}$ & 125 & $220(310)$ & $400(510)$ & 620 \\
\hline $\begin{array}{c}\text { Aftershock Epicenter PGA, } \\
\boldsymbol{A}_{\boldsymbol{a}}\left(\mathbf{c m} / \mathbf{s}^{\mathbf{2}}\right)\end{array}$ & 115 & $125(220)$ & $220(310)$ & 310 \\
\hline
\end{tabular}

The data in round brackets are the corresponding values of $0.15 \mathrm{~g}$ and $0.30 \mathrm{~g}$ basic acceleration.

TABLE III. RELATIONSHIP BETWEEN EPICENTER INTENSITY AND GROUND MOTION DURATION

\begin{tabular}{|c|c|c|c|c|}
\hline $\begin{array}{c}\text { Main Shock Epicenter } \\
\text { Intensity, } \boldsymbol{I}_{\boldsymbol{m}}\end{array}$ & $\mathbf{6}$ & $\mathbf{7}$ & $\mathbf{8}$ & $\mathbf{9}$ \\
\hline $\begin{array}{c}\text { Main Shock Duration, } \\
\boldsymbol{T}_{\mathrm{sm}}(\mathbf{s})\end{array}$ & 7.52 & $\begin{array}{c}10.16 \\
(12.13)\end{array}$ & $\begin{array}{c}14.48 \\
(17.29)\end{array}$ & 20.65 \\
\hline $\begin{array}{c}\text { Aftershock Duration, } \\
\boldsymbol{T}_{\mathrm{sa}}(\mathbf{s})\end{array}$ & 5.5 & $\begin{array}{c}6.48 \\
(7.12)\end{array}$ & $\begin{array}{c}7.92 \\
(8.51)\end{array}$ & 9.46 \\
\hline
\end{tabular}

The data in round brackets are the corresponding values of $0.15 \mathrm{~g}$ and $0.30 \mathrm{~g}$ basic acceleration.

TABLE IV. RELATIONSHIP BETWEEN INTENSITY AND SPECTRUM INTENSITY FACTOR IN EPICENTER

\begin{tabular}{|c|c|c|c|c|}
\hline $\begin{array}{c}\text { Main Shock Epicenter } \\
\text { Intensity, } \boldsymbol{I}_{\boldsymbol{m}}\end{array}$ & $\mathbf{6}$ & $\mathbf{7}$ & $\mathbf{8}$ & $\mathbf{9}$ \\
\hline $\begin{array}{c}\text { Main Shock Spectrum } \\
\text { Density Factor, } \boldsymbol{S}_{\boldsymbol{0} \boldsymbol{m}}\end{array}$ & 89 & $199(298)$ & $493(816)$ & 1221 \\
\hline $\begin{array}{c}\text { Aftershock Spectrum } \\
\text { Density Factor, } \boldsymbol{S}_{\boldsymbol{0} \boldsymbol{a}}\end{array}$ & 82 & $89(144)$ & $144(199)$ & 199 \\
\hline
\end{tabular}

The data in round brackets are the corresponding values of $0.15 \mathrm{~g}$ and $0.30 \mathrm{~g}$ basic acceleration.

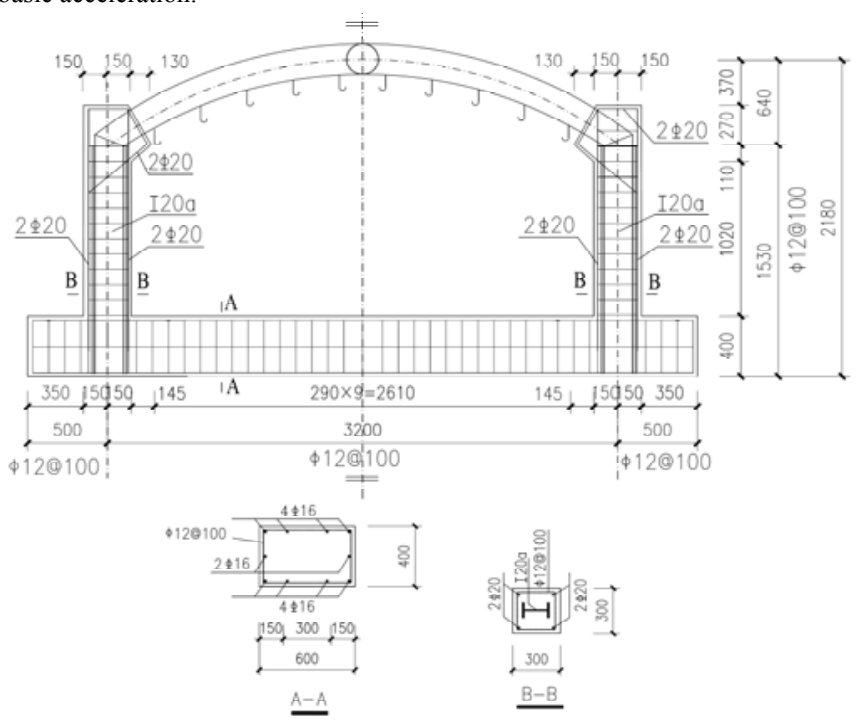

FIGURE I. CONSTRUCTION PLANS OF STRUCTURE

\section{B. Equivalent Earthquake Wave}

Seven acceleration time history curves of main shocks were selected by YJK software. According to the statistical relationship between aftershock and its main shock, seven acceleration time curves of aftershocks can be determined, then 49 acceleration time history curves of equivalent 
earthquake manufactured by adding aftershock just behind main shock. Suppose earthquake group is first, seismic fortification intensity is 7 , basic acceleration is $0.10 \mathrm{~g}$, site classification is II, and $T_{\mathrm{g}}=0.35 \mathrm{~s}$, then earthquake wave characteristic values can get from TABLE I IV, it is shown in TABLE V.

\section{Equivalent Earthquake Damage Model}

Structural damage in main shock can be expressed as follow in [10]:

$$
D_{m}=\frac{x_{m}}{x_{d}}+\beta \frac{E_{h}}{f_{y} x_{d}}
$$

$x_{m}$ for peak displacement, $x_{d}$ for ultimate displacement, $E_{h}$ for hysteretic energy dissipation, $f_{y}$ for yield strength and $\beta$ for damage parameter. Neglected change of $x_{m}, x_{d}, \beta$ and $f_{y}$ between equivalent earthquake and mian shock, aggravation of damage can be expressed as increase of input energy in equivalent earthquake. By introducing damage index correction coefficient $(\gamma),(8)$ can be expressed as follow:

$$
D_{E}=\frac{x_{m}}{x_{d}}+\gamma \beta \frac{E_{h}}{f_{y} x_{d}}
$$

\section{Evolution Law Damage Index Correction Coefficient}

Consider change of seismic fortification intensity, the mean values of damage index correction coefficients are shown in TABLE VI by inputting main shock and equivalent earthquake seismic wave respectively. It is obvious that lower fortification intensity is, bigger damage index correction coefficient is. With increase of fortification intensity, damage index correction coefficient gradually tends to be stable. By fitting the data of TABLE VI, regression equation between PGA and damage index correction coefficient can be established as follows:

$$
\gamma=\left(4.33 A_{m}{ }^{2}-4600 A_{m}+2.47\right) \times 10^{-6}
$$

\section{E. Structural Damage Analysis}

When fortification intensity change, damage indexes of main shock and Equivalent earthquake can be calculated as shown in TABLE VII. Damage index increased about $7 \% \sim 20 \%$ by thinking of single strongest aftershock, lower fortification intensity is, bigger damage index increase.

\section{F. Effectiveness Analysis of Damage Correction Model}

To verify the damage correction model, ABAQUS finite element analysis software also introduced to calculate damage index correction coefficient and damage index. With PGA increase, damage index correction coefficient of two software calculated are shown in FIGURE II. Although the results of ABAQUS are slightly larger than that of YJK, they tend to be coincide in general.
TABLE V. CHARACTERS VALUE OF SEISMIC WAVES

\begin{tabular}{|c|c|c|c|}
\hline Seismic Wave & PGA(cm/s $\mathbf{s}^{\mathbf{2}}$ & $\mathbf{S}_{\mathbf{0}}$ & $T_{s}(\mathbf{s})$ \\
\hline Main Shock & 220 & 199 & 10.16 \\
\hline Aftershock & 125 & 89 & 6.48 \\
\hline Equivalent Earthquake & 220 & 199 & 16.64 \\
\hline
\end{tabular}

\begin{tabular}{|c|c|c|c|c|}
\hline \multirow{2}{*}{$\begin{array}{c}\text { Fortification } \\
\text { intensity }\end{array}$} & \multirow{2}{*}{$\begin{array}{c}\text { Maximum } \\
\text { floor } \\
\text { displacement } \\
(\mathbf{m m})\end{array}$} & \multicolumn{2}{|c|}{ Hysteretic energy(J) } & \multirow{2}{*}{$\begin{array}{c}\text { Damage } \\
\text { index } \\
\text { correction } \\
\text { coefficient } \\
\gamma\end{array}$} \\
\hline & & $\begin{array}{l}\text { Main } \\
\text { shock }\end{array}$ & $\begin{array}{l}\text { Equivalent } \\
\text { earthquake }\end{array}$ & \\
\hline $6(0.05 g)$ & 3.74 & 1832 & 3646 & 1.99 \\
\hline $7(0.10 \mathrm{~g})$ & 7.93 & 6267 & 10152 & 1.62 \\
\hline $7(0.15 g)$ & 14.64 & 19661 & 28286 & 1.44 \\
\hline $8(0.20 \mathrm{~g})$ & 26.31 & 32461 & 43536 & 1.34 \\
\hline $8(0.30 \mathrm{~g})$ & 41.52 & 33833 & 43328 & 1.28 \\
\hline $9(0.40 \mathrm{~g})$ & 62.18 & 48476 & 60821 & 1.25 \\
\hline
\end{tabular}

TABLE VI. SEISMIC RESPONSE ANALYSIS RESULTS OF STRUCTURE FOR DIFFERENT INTENSITIES

\begin{tabular}{|c|c|c|c|c|}
\hline \multirow[b]{2}{*}{$\begin{array}{l}\text { Fortification } \\
\text { intensity }\end{array}$} & \multirow[b]{2}{*}{$\begin{array}{c}\text { PGA of Main } \\
\text { Shock } \\
\left(\mathrm{cm} / \mathrm{s}^{2}\right)\end{array}$} & \multicolumn{2}{|c|}{ Damage Index } & \multirow{2}{*}{ 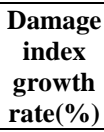 } \\
\hline & & $\begin{array}{l}\text { Main } \\
\text { Shock }\end{array}$ & $\begin{array}{l}\text { Equivalent } \\
\text { Earthquake }\end{array}$ & \\
\hline 6 (0.05g) & 125 & 0.07 & 0.09 & 20.07 \\
\hline 7 (0.10g) & 220 & 0.18 & 0.21 & 18.03 \\
\hline 7 (0.15g) & 310 & 0.39 & 0.46 & 18.02 \\
\hline 8 (0.20g) & 400 & 0.68 & 0.77 & 13.32 \\
\hline $8(0.30 \mathrm{~g})$ & 510 & 0.93 & 1.00 & 8.34 \\
\hline $9(0.40 \mathrm{~g})$ & 620 & 1.37 & 1.47 & 7.34 \\
\hline
\end{tabular}

TABLE VII. SUMMARY FOR DAMAGE INDEX AND ITS GROWTH RATION

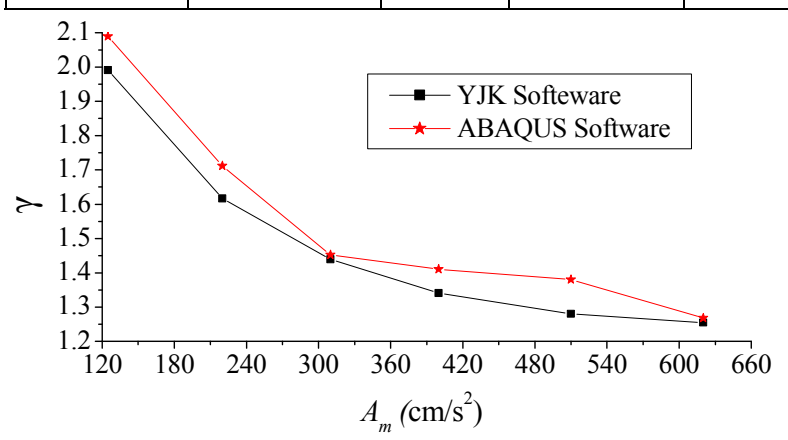

FIGURE II. RELATIONSHIP BETWEEN DAMAGE INDEX CORRECTION COEFFICIENT AND PEAK ACCELERATION VALUE OF MAIN SHOCKS

With PGA increase, calculated damage index growth curves of two software are shown in FIGURE III. In general, the results of two software are in good agreement when PGA is low. Damage index increased with PGA, and ABAQUS 
results are slightly smaller than that of YJK. There are about $7 \% \sim 24 \%$ increases of damage index.

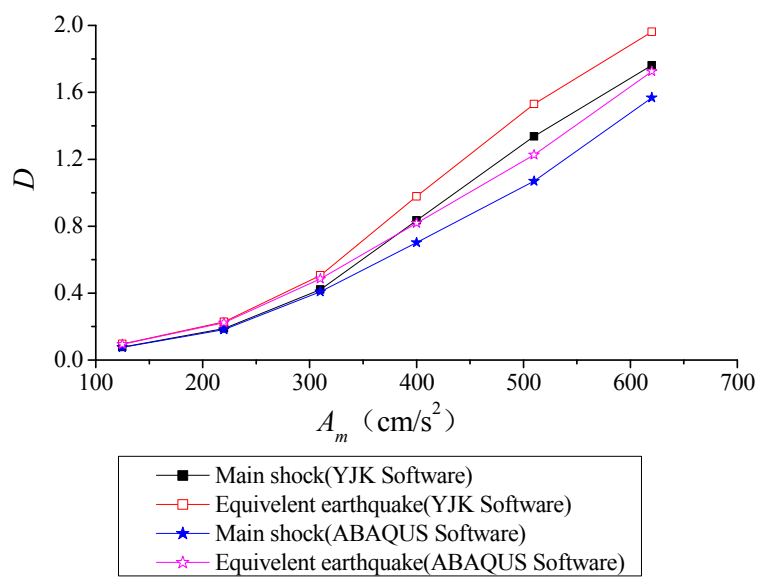

FIGURE III. CONTRASTIVE CURVE OF DAMAGE INDEX OF STRUCTURE

\section{CONCLUSION}

On the basis of statistical analysis, quantitative method of single strongest aftershock model parameters has carried out, a modified Park-Ang model with damage index correction coefficient has proposed, then damage indexes of CFST arch column structure in different fortification intensity and PGA have calculated with two software. The results show as follows:

1) Aftershock intensity can be obtained by reducing $0.5,1,1.5$ or 2 according to basic fortification intensity $6,7,8$ or 9.

2) Damage index of CFST arch column structure increase about 7\% 24\% when single strongest aftershock has taken part in.

3) By introducing damage index correction coefficient, a simple and practical seismic damage model proposed,which proved relatively reliable within a certain range.

\section{ACKNOWLEDGMENT}

Thanks China Earthquake Networks Center (CENC) and Pacific Earthquake Engineering Research Center (PEER) for supporting 68 sets data. The paper are supported by National Natural Science Foundation of China (No: 11272095, No:51378133).

\section{REFERENCES}

[1] Park Y J , Ang A H-S, Wen Y K. "Concrete seismic damage model". Structural engineering, ASCE, vol.111, pp.722-739. 4,1985.

[2] Niu D T. "Based on random dynamic analysis of elastic plastic seismic structure probability design theory and method". Harbin Construction Engineering Institute, 1991.

[3] Xiao M K. "Analysis method of displacement and energy responses for evaluating the performance of seismic structures". Chongqing University, 2004

[4] Bo $\mathrm{Wu}$, Jinping Ou. "Statistical relationship between magnitude of mainshock and aftershock and parameters of earthquake ground motion".
Earthquake engineering and engneering vibration, vol.13, pp.28-34, 3,1993.

[5] Bo $\mathrm{Wu}$, Jinping Ou. "The exploration of probabilistic accumulated damage of structures under several earthquakes".Proceedings of the third National Symposium on academic exchanges. Nanjing: Structural reliability Committee of Civil Engineering Society of China, pp.346$353,1992$.

[6] Bo Wu, Jinping Ou.'Practical method for aseismic design considering the influences of aftershocks".Journal of Harbin university of civil engineering and architecture, vol.27,pp.9-16, 4,1994.

[7] Yong Xu. "Study on seismic statistical model of single strongest aftershock," unpublished.

[8] Yayong Wang, Li Hong. Statistical analysis of ground motion parameters considering the characteristics of the ground motions [J]. earthquake engineering and engineering vibration, 1986, 6 (03): 67-77.

[9] Jinping Ou, Ditao Niu, Xiuli Du. Design of random ground motion model and its parameter determination $[\mathrm{J}]$. Earthquake engineering and engineering vibration, 1991, 11 (03): 45-54.

[10] Park Y J, Ang A H-S, Wen Y K. concrete structure engineering seismic damage model of [J]., ASCE, 1985, 111 (4): 722-739. (English Edition) 